\title{
Allopurinol reverses mercaptopurine-induced hypoglycemia in patients with acute lymphoblastic leukemia [version 1; peer
} review: 2 approved]

\author{
Melissa Zhang1', Bruce Bostrom (iD2 \\ ${ }^{1}$ University of California, Berkeley, Berkeley, CA, 94720, USA \\ ${ }^{2}$ Department of Pediatric Oncology, Children's Hospitals and Clinics of Minnesota, Minneapolis, MN, 55404, USA
}

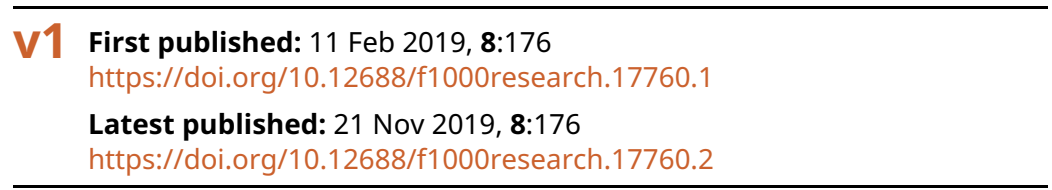

\section{Abstract}

Fasting hypoglycemia is a known complication of mercaptopurine (6MP) maintenance therapy for acute lymphoblastic leukemia (ALL). It is associated with high levels of the methylated metabolite 6-methylmercaptopurine (6MMP). Symptoms of hypoglycemia include morning tremulousness, nausea and vomiting. We have previously shown that switching 6MP dosing from evening to morning resolved hypoglycemia by reducing 6MMP; however, the reduction of 6MMP was only transient, potentially resulting in return of hypoglycemia. In children and adults with Crohn's disease, co-prescribing allopurinol with 6MP blocks the activity of thiopurine methytransferase (TPMT), reducing $6 \mathrm{MMP}$ and improving its tolerance. As a consequence of inhibiting TPMT, 6MP is shunted toward the production of 6thioguanine nucleotide (6TGN), which will result in pancytopenia if the dose of $6 \mathrm{MP}$ is not reduced. We demonstrate that allopurinol with a reduced dose of 6MP in two patients with ALL and 6MMP-associated hypoglycemia resulted in a complete and sustained suppression of $6 \mathrm{MMP}$ and rapid reversal of hypoglycemia and its symptoms.

\section{Keywords}

mercaptopurine, allopurinol, hypoglycemia, morning nausea, thiopurine methyltransferase

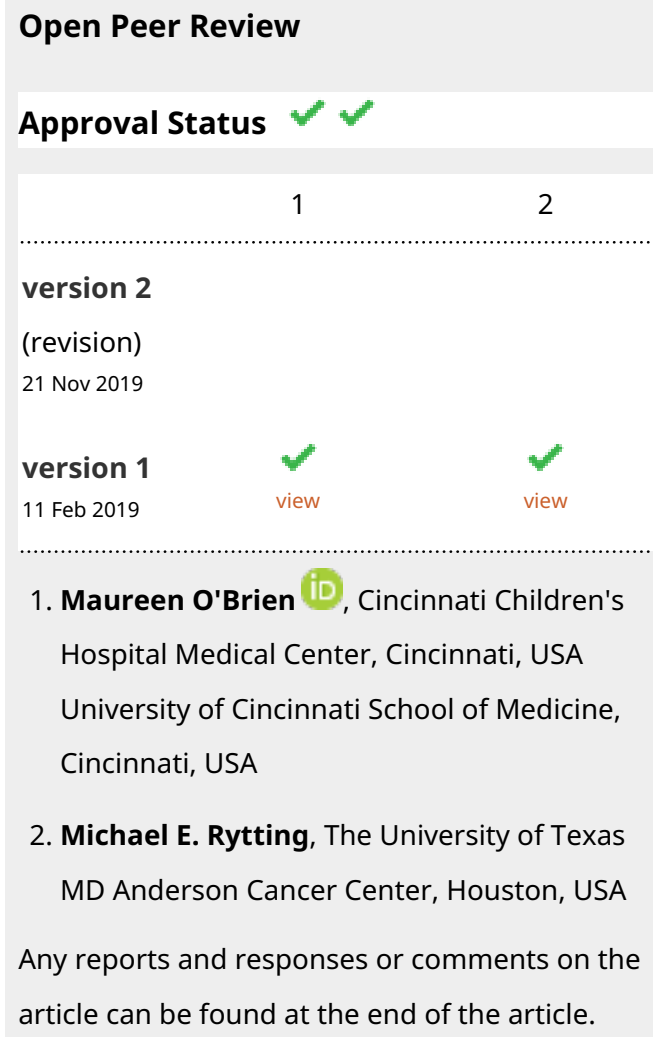

1 2

version 2

(revision)

21 Nov 2019

version 1

11 Feb 2019

1. Maureen O'Brien ID, Cincinnati Children's

Hospital Medical Center, Cincinnati, USA

University of Cincinnati School of Medicine,

Cincinnati, USA

2. Michael E. Rytting, The University of Texas MD Anderson Cancer Center, Houston, USA

Any reports and responses or comments on the article can be found at the end of the article. 
Corresponding author: Bruce Bostrom (Bruce.Bostrom@childrensmn.org)

Author roles: Zhang M: Data Curation, Visualization, Writing - Original Draft Preparation; Bostrom B: Conceptualization, Formal Analysis

Competing interests: No competing interests were disclosed.

Grant information: The author(s) declared that no grants were involved in supporting this work.

Copyright: @ 2019 Zhang M and Bostrom B. This is an open access article distributed under the terms of the Creative Commons Attribution License, which permits unrestricted use, distribution, and reproduction in any medium, provided the original work is properly cited.

How to cite this article: Zhang $M$ and Bostrom B. Allopurinol reverses mercaptopurine-induced hypoglycemia in patients with acute lymphoblastic leukemia [version 1; peer review: 2 approved] F1000Research 2019, 8:176

https://doi.org/10.12688/f1000research.17760.1

First published: 11 Feb 2019, 8:176 https://doi.org/10.12688/f1000research.17760.1 


\section{Introduction}

Mercaptopurine (6MP) maintenance therapy is critical for the cure of ALL. There is no acceptable alternative. In general, $6 \mathrm{MP}$ is well tolerated with minimal side-effects such as facial or generalized rash and asymptomatic elevations of hepatic transaminases. Occasionally, more serious side effects, such as direct hyperbilirubinemia, pancreatitis, and fasting hypoglycemia, may occur, requiring discontinuation or reduction in the dose of $6 \mathrm{MP}^{1}$

Previously, we had shown that 6MP induced fasting hypoglycemia is related to elevated levels of red cell 6-methylmercaptopurine $(6 \mathrm{MMP})^{2}$. We also showed that altering the administration time of 6MP from evening to morning or splitting the dose to twice a day results in lower 6MMP concentrations and resolution of hypoglycemia symptoms. However, in some of the patients there was a rebound in 6MMP, which may result in recurrence of symptomatic hypoglycemia.

Allopurinol has been used by gastroenterologists for many years in patients with inflammatory bowel disease who have elevations of alanine aminotransferase (ALT) or gastrointestinal symptoms from the use of $6 \mathrm{MP}$ or azathioprine ${ }^{3-6}$. Recently, pediatric patients with ALL have been treated with allopurinol to reduce elevated 6MMP levels resulting in pancreatitis, hepatotoxicity, or inability to get absolute neutrophil count in target range despite increasing the dose of $6 \mathrm{MP}^{7-9}$.

\section{Case series}

The electronic medical records of two children with ALL who developed symptomatic hypoglycemia on maintenance therapy were reviewed. After an extensive risk-benefit discussion with parents, they were started on allopurinol with a reduced dose of 6MP.

Thiopurine metabolites were measured with a CLIA-approved test (www.prometheuslabs.com). The reference values for this assay only apply to patients with inflammatory bowel disease on azathioprine or 6MP and not for ALL patients on 6MP. Unpublished data on 200 patients with ALL from day 85 of the first maintenance cycle on Children's Oncology Group COG1922 demonstrated the $5^{\text {th }}, 50^{\text {th }}$, and $95^{\text {th }}$ percentiles for $6 \mathrm{MMP}$ are 320,4900 , and $19,000 \mathrm{pmol} / 8 \times 10^{8} \mathrm{RBC}$, respectively. The $5^{\text {th }}, 50^{\text {th }}$, and $95^{\text {th }}$ percentiles for $6 \mathrm{TGN}$ are 75,260 , and 690 $\mathrm{pmol} / 8 \times 10^{8} \mathrm{RBC}$, respectively ${ }^{10}$. This two-patient case report was reviewed by Children's Minnesota Institutional Review Board and deemed not research allowing publication.

\section{Case 1}

Patient UPN 1 is an African-American girl who was diagnosed with B-lineage ALL at age 10 years. She was enrolled on high-risk protocol Children's Oncology Group (COG) AALL1131 (ClinicalTrials.gov Identifier: NCT02883049), but was taken off protocol after induction due to desire to use triple intrathecal therapy for blasts in diagnostic cytospin (CNS-2 status). Germline testing for methylene tetrahydrofolate reductase (MTHFR C667T) and thiopurine methyltransferase (TPMT) were homozygous normal.
Maintenance therapy doses were started at $6 \mathrm{MP}\left(62 \mathrm{mg} / \mathrm{m}^{2} /\right.$ day $)$ and MTX $\left(15 \mathrm{mg} / \mathrm{m}^{2} /\right.$ week $)$. On day 57 of maintenance, the dose of $6 \mathrm{MP}$ was increased to $75 \mathrm{mg} / \mathrm{m}^{2} /$ day with no change in the methotrexate (MTX) dose. On day 73, she presented to the emergency department with shaking. Upon questioning she disclosed having episodes of morning shaking, nausea and vomiting for about a month. Serum glucose was $3.18 \mathrm{mmol} / \mathrm{L}$ (53 mg/dL). The hemoglobin A1C level was 4.9\%. Thiopurine metabolites showed an extremely elevated 6MMP level of $41,000 \mathrm{pmol} / 8 \times 10^{8} \mathrm{RBC}$ and $6 \mathrm{TGN}$ level of $456 \mathrm{pmol} / 8 \times 10^{8}$ RBC. She was neutropenic with absolute neutrophil count (ANC) of $0.462 \times 10^{9}$ cells $/ \mathrm{L}$ so oral chemotherapy was halted.

On day 98, 6MP was restarted at $30 \mathrm{mg} / \mathrm{m}^{2} /$ day along with $50 \mathrm{mg}$ of allopurinol given with each dose of 6MP. MTX was also restarted at the previous dose. The episodes of morning nausea, vomiting, and shakes resolved. No further episodes of hypoglycemia were seen. On day 142 , the ANC was $0.29 \times 10^{9}$ cells/L, so oral chemotherapy was halted. Subsequently the hemoglobin level fell to $57 \mathrm{~g} / \mathrm{L}$ and platelets to $82,000 / \mu \mathrm{l}$. On day 163, 6MP was restarted at $15 \mathrm{mg} / \mathrm{m}^{2} /$ day with $50 \mathrm{mg}$ allopurinol and the previous MTX dose, which continued to the end of therapy without interruption. MTX dose remained unchanged at $75 \mathrm{mg} / \mathrm{m}^{2} /$ week and $6 \mathrm{MP}$ was increased to $18 \mathrm{mg} / \mathrm{m}^{2} /$ day to keep ANC within the target range $\left(0.5-2 \times 10^{8} / \mathrm{L}\right)$. The patient remains in remission 24 months off therapy. Figure 1 contains details of oral chemotherapy doses and laboratory values.

\section{Case 2}

Patient UPN 2 is a Caucasian girl diagnosed with B-lineage ALL at 3 years of age. Genotyping for TPMT was normal and MTHFR C677T was heterozygous. She was enrolled on the standard risk protocol COG AALL0932 (ClinicalTrials.gov Identifier: NCT01190930) and removed from the protocol when allopurinol was started.

Around day 124 of maintenance, she had problems with morning vomiting daily. She had been on full dose $6 \mathrm{MP}\left(75 \mathrm{mg} / \mathrm{m}^{2} /\right.$ day) and MTX (20 mg/m $/$ week) since the start of maintenance with no interruptions. On day 229, she was diagnosed steroid-induced hyperglycemia with rebound hypoglycemia. Hemoglobin A1C was normal. Home glucose monitoring was started. Glucose levels were noted to be elevated after completion of a 5-day dexamethasone pulse. Metformin $500 \mathrm{mg}$ extended release every morning was started with a subsequent dexamethasone pulse on day 255, with the resolution of steroid induced hyperglycemia. However symptomatic hypoglycemia continued.

Thiopurine metabolite levels were drawn, which showed an extremely high $6 \mathrm{MMP}$ level $\left(32,718 \mathrm{pmol} / 8 \times 10^{8} \mathrm{RBC}\right)$ with a 6 TGN level of $182 \mathrm{pmol} / 8 \times 10^{8} \mathrm{RBC}$. She then was switched to morning dosing of $6 \mathrm{MP}$, based on prior publication ${ }^{2}$. She continued to have symptoms of morning hypoglycemia, which was confirmed on five low serum glucose values over a 40-day period (values of $46,44,42,37$, and $36 \mathrm{mg} / \mathrm{dL}=2.8,2.7,2.6$, $2.5,2.2$, and $2.2 \mathrm{mmol} / \mathrm{L}$ ). 


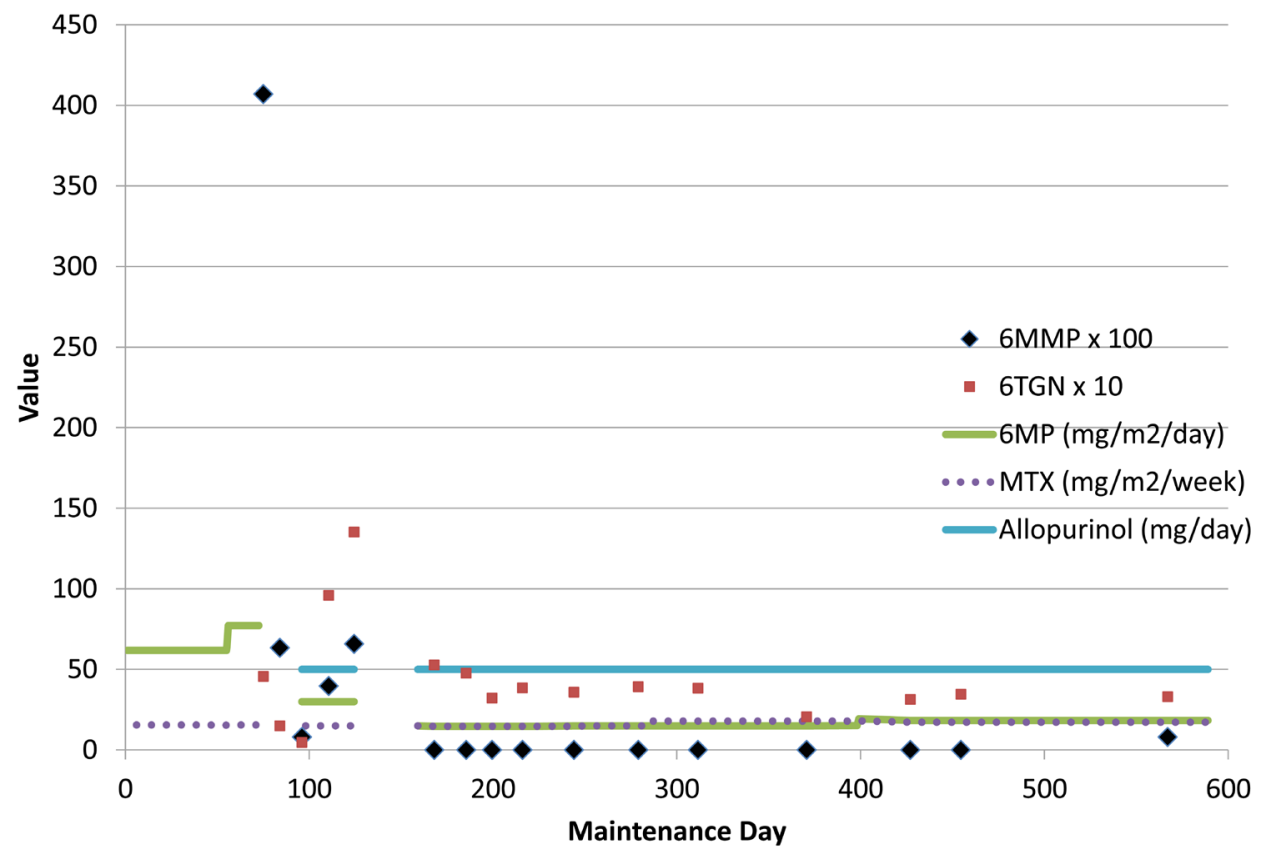

Figure 1. Treatment regimen for patient in Case 1. On the horizontal axis is the day of maintenance therapy from the start to completion. On the vertical axis are the red cell thiopurine metabolite values and drug doses. Interruption in drug doses is noted by a break in the line. For graph clarity, 6-methyl-mercaptopurine (6MMP) values were divided by 100 and 6-thioguanine nucleotide (6TGN) values by 10 . After introduction of allopurinol, the 6MMP levels rapidly fell to undetectable levels with stable 6TGN. Following the initial introduction of allopurinol in patient 1 the mercaptopurine (6MP) and methotrexate (MTX) doses required interruption due to neutropenia which did not recur with a dose reduction of 6MP. As expected the myelosuppression was associated with a very elevated 6TGN level.

After extensive discussion with the parents concerning the risks and benefits of the treatment, she was taken off COG 0932 protocol per physician preference and started on allopurinol $50 \mathrm{mg}$ daily with reduced dose $6 \mathrm{MP}\left(12 \mathrm{mg} / \mathrm{m}^{2} / \mathrm{day}\right)$ and MTX $\left(11 \mathrm{mg} / \mathrm{m}^{2} /\right.$ day) on day 316 of maintenance. Within 2 weeks she had no hypoglycemia symptoms and no low glucose values on home testing. On day 392 the doses were increased to 6MP (20 $\mathrm{mg} / \mathrm{m}^{2} /$ day and MTX (17 $\mathrm{mg} / \mathrm{m}^{2} /$ week) to keep ANC in the target range $\left(0.5-2 \times 10^{8} / \mathrm{L}\right)$. Metformin was continued for 5 months during dexamethasone pulses. Metformin was omitted the last 5 months of maintenance, without rebound hyperglycemia, which was completed on day 547. She remains in remission 24 months off therapy. Figure 2 contains details of oral chemotherapy doses and laboratory values.

\section{Discussion}

$6 \mathrm{MP}$ is a pro-drug that is metabolized in nucleated cells to form 6TGN, which is felt to be the active anti-leukemic metabolite. Alternatively, 6MP can also undergo oxidation through a pathway catalyzed by xanthine oxidase/dehydrogenase and aldehyde oxidase to form thiouric acid, which is excreted in urine. It is also metabolized in nucleated cells by TPMT, producing 6MMP. In patients with inflammatory bowel disease, high levels of $6 \mathrm{MMP}$ ( $\left.>5300 \mathrm{pmol} / 8 \times 10^{8} \mathrm{RBCs}\right)$ have been associated with hepatotoxicity, decreased therapeutic efficacy, and symptoms of hypoglycemia ${ }^{11}$.
Previously we showed that switching 6MP from evening to morning administration reduced elevated 6MMP levels and resolved symptomatic hypoglycemia ${ }^{2}$. The mechanism of this effect is not fully known, but the most reasonable interpretation is inhibition of TPMT activity. The current study is an extension of that observation, showing that co-administration of a low dose allopurinol $(50 \mathrm{mg})$ once a day with a reduced dose of 6MP ( 20 $\mathrm{mg} / \mathrm{m}^{2} /$ day) also resolves 6MMP-induced symptomatic hypoglycemia without any rebound of 6MMP levels, as we saw with switching the administration time of 6MP. A reduction in the dose of $6 \mathrm{MP}$ is needed because on average the 6MMP to 6TGN ratio during ALL maintenance is approximately 25 to 1 , per unpublished data from the COG9506 study ${ }^{12}$.

Approximately $90 \%$ of people, including the patients in this study, have wild-type TPMT, the genotype responsible for high levels of TPMT activity. These patients require higher doses of $6 \mathrm{MP}$ to reach therapeutic levels of 6TGN. It is unknown what proportion of these patients will develop the symptoms related to elevated $6 \mathrm{MMP}^{8}$.

Allopurinol was first developed by Gertrude Elion to potentiate the therapeutic index of oral 6MP for treatment of leukemia. Albeit allopurinol stimulated the anti-tumor activity of 6MP, it was associated with increased hematologic toxicity. Allopurinol use with 6MP was abandoned in the 1960s and fell into the 


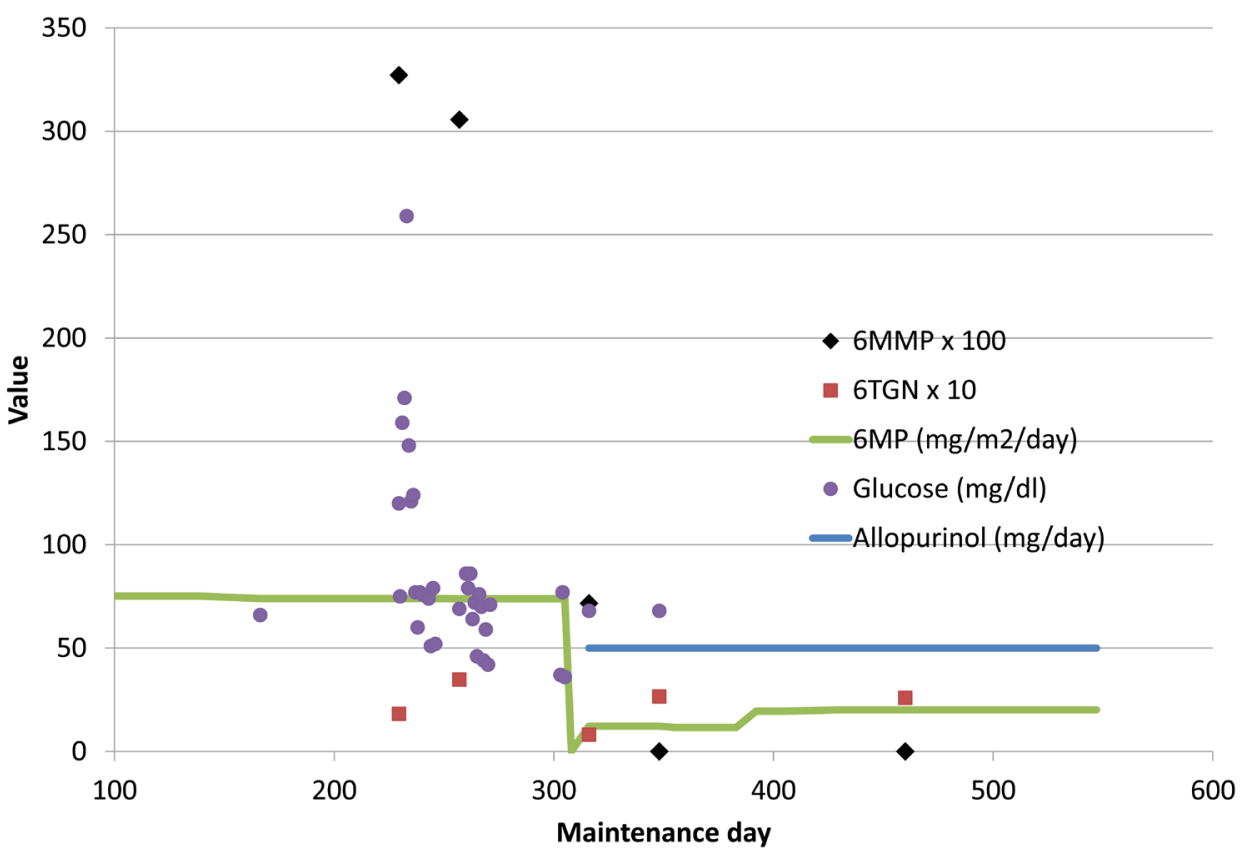

Figure 2. Treatment regimen for patient in Case 2. On the horizontal axis is the day of maintenance therapy from the start to completion. On the vertical axis are the red cell thiopurine metabolite values and drug doses. For graph clarity, 6-methyl-mercaptopurine (6MMP) values were divided by 100 and 6-thioguanine nucleotide (6TGN) values by 10. After introduction of allopurinol, the 6MMP levels rapidly fell to undetectable levels with stable 6TGN. Of note the high glucose values during dexamethasone pulses resolved after introduction of metformin on day 255.

niche of managing gout. However, our data shows success of co-prescription of allopurinol to reverse hypoglycemia in children with ALL by reducing $6 \mathrm{MMP}^{13}$.

Seinen et al. demonstrated that allopurinol inhibited xanthine oxidase/dehydrogenase and increased hypoxanthine guanine phosphoribosal transferase in blood samples from patients taking 6MP who were started on allopurinol ${ }^{14}$. Notably, they did not show change in TPMT activity but did show a slight increase in 6TGN and significant decrease in 6MMP. However, Blaker et al. demonstrated inhibition of TPMT by a metabolite of allopurinol thioxanthine (2-hydroxymercaptopurine) in vitro $^{11}$. Our data shows that the same mechanism of allopurinol to inhibit TPMT to treat hepatotoxicity in IBD can be applied to reverse symptoms of hypoglycemia by lowering 6MMP levels. Both patients exhibited a reduction of 6MMP to undetectable levels following co-prescription of allopurinol with $6 \mathrm{MP}$.

Of concern is the theoretical possibility that reducing production of 6MMP may have a negative effect on leukemia therapy. An in vitro study with MOLT-4 ALL cells showed that knocking down TPMT expression did not affect sensitivity to 6MP, and that increasing the $6 \mathrm{MMP}$ to $6 \mathrm{TGN}$ ratio in the MOLT-4 ALL cell line by adding S-adenosylmethionine (SAM) decreases cytotoxicity of $6 \mathrm{MP}^{15,16}$. These two prior studies suggest $6 \mathrm{MMP}$ is not an active metabolite in the treatment of leukemia. However, another in vitro study showed that transfection with TPMT gene increased sensitivity to $6 \mathrm{MP}$ in human CCRF-CEM cell lines, probably through inhibition of de novo purine synthesis by methylmercaptopurine nucleotide ${ }^{17}$. To our knowledge, no studies on animals or humans, including currently unpublished results from the COG1922/B925 study, have demonstrated a correlation of intracellular levels of 6MMP with a decrease in ALL relapse. Thus, we are left with conflicting in vitro data and no patient data suggesting that $6 \mathrm{MMP}$ is necessary to cure ALL. Indeed, when prescribed by itself, allopurinol is also known to inhibit de novo purine synthesis, similar to the effect of 6MMP, suggesting it may have anti-leukemic effects. Following the submission of our manuscript the senior author reviewed for publication a two patient report further confirming our observations ${ }^{18}$. In our opinion, the benefit of preventing symptomatic 6MMP-induced hypoglycemia, and the likely reduction or omission of 6MP, outweighs the unproven theoretical possibility of interfering with ALL therapy.

\section{Data availability}

Deidentified clinical values for each patient by day are available on figshare. DOI: https://doi.org/10.6084/m9.figshare.7666409'9 .

Data are available under the terms of the Creative Commons Attribution 4.0 International license (CC-BY 4.0).

\section{Consent}

Written informed consent for publication of their clinical details was obtained from the parents of the patients.

\section{Grant information}

The author(s) declared that no grants were involved in supporting this work. 
1. Schmiegelow K, Nielsen SN, Frandsen TL, et al:: Mercaptopurine/Methotrexate maintenance therapy of childhood acute lymphoblastic leukemia: clinical facts and fiction. J Pediatr Hematol Oncol. 2014; 36(7): 503-517. PubMed Abstract | Publisher Full Text | Free Full Text

2. Melachuri S, Gandrud L, Bostrom B: The association between fasting hypoglycemia and methylated mercaptopurine metabolites in children with acute lymphoblastic leukemia. Pediatr Blood Cancer. 2014; 61(6): 1003-1006. PubMed Abstract | Publisher Full Text

3. Sparrow MP, Hande SA, Friedman S, et al.: Allopurinol safely and effectively optimizes tioguanine metabolites in inflammatory bowel disease patients not responding to azathioprine and mercaptopurine. Aliment Pharmacol Ther. 2005; 22(5): 441-446.

PubMed Abstract | Publisher Full Text

4. Smith MA, Blaker P, Marinaki AM, et al.: Optimising outcome on thiopurines in inflammatory bowel disease by co-prescription of allopurinol. J Crohns Colitis. 2012; 6(9): 905-912.

PubMed Abstract | Publisher Full Text

5. Min MX, Weinberg DI, McCabe RP: Allopurinol enhanced thiopurine treatment for inflammatory bowel disease: safety considerations and guidelines for use. J Clin Pharm Ther. 2014; 39(2): 107-111.

PubMed Abstract | Publisher Full Text

6. Ihekweazu FD, Kellermayer R: Allopurinol: a useful adjunct to thiopurine therapy for pediatric ulcerative colitis in the biologic era. $J$ Pediatr Gastroenterol Nutr. 2014; 59(1): 22-24.

PubMed Abstract | Publisher Full Text

7. Zerra P, Bergsagel J, Keller FG, et al:: Maintenance Treatment With Low-Dose Mercaptopurine in Combination With Allopurinol in Children With Acute Lymphoblastic Leukemia and Mercaptopurine-Induced Pancreatitis. Pediatr Blood Cancer. 2016; 63(4): 712-715.

PubMed Abstract | Publisher Full Tex

8. Giamanco NM, Cunningham BS, Klein LS, et al:: Allopurinol Use During Maintenance Therapy for Acute Lymphoblastic Leukemia Avoids Mercaptopurine-related Hepatotoxicity. J Pediatr Hematol Oncol. 2016; 38(2): 147-151.

PubMed Abstract | Publisher Full Text

9. Brackett J, Schafer ES, Leung $\mathrm{DH}$, et al:: Use of allopurinol in children with acute lymphoblastic leukemia to reduce skewed thiopurine metabolism. Pediatr Blood Cancer. 2014; 61(6): 1114-1117. PubMed Abstract | Publisher Full Text

10. Bostrom BC, Sensel MR, Sather HN, et al.: Dexamethasone versus prednisone and daily oral versus weekly intravenous mercaptopurine for patients with standard-risk acute lymphoblastic leukemia: a report from the Children's Cancer Group. Blood. 2003; 101(10): 3809-17.

PubMed Abstract | Publisher Full Text

11. Blaker PA, Arenas-Hernandez M, Smith MA, et al:: Mechanism of allopurinol induced TPMT inhibition. Biochem Pharmacol. 2013; 86(4): 539-547. PubMed Abstract | Publisher Full Text

12. Bell BA, Brockway GN, Shuster JJ, et al: A comparison of red blood cell thiopurine metabolites in children with acute lymphoblastic leukemia who received oral mercaptopurine twice daily or once daily: a Pediatric Oncology Group study (now The Children's Oncology Group). Pediatr Blood Cancer. 2004; 43(2): 105-9. PubMed Abstract | Publisher Full Text

13. Elion GB: Nobel lecture in physiology or medicine--1988. The purine path to chemotherapy. In Vitro Cell Dev Biol. 1989; 25(4): 321-30. PubMed Abstract

14. Seinen ML, van Asseldonk DP, de Boer NK, et al:: The effect of allopurinol and low-dose thiopurine combination therapy on the activity of three pivotal thiopurine metabolizing enzymes: results from a prospective pharmacological study. J Crohns Colitis. 2013; 7(10): 812-819.

PublMed Abstract | Publisher Full Text

15. Karim $\mathrm{H}$, Ghalali $\mathrm{A}$, Lafolie $\mathrm{P}$, et al.: Differential role of thiopurine methyltransferase in the cytotoxic effects of 6-mercaptopurine and 6thioguanine on human leukemia cells. Biochem Biophys Res Commun. 2013; 437(2): 280-6.

PubMed Abstract | Publisher Full Text

16. Milek M, Karas Kuzelicki N, Smid A, et al:: S-adenosylmethionine regulates thiopurine methyltransferase activity and decreases 6-mercaptopurine cytotoxicity in MOLT lymphoblasts. Biochem Pharmacol. 2009; 77(12): 1845-1853. PubMed Abstract | Publisher Full Text

17. Dervieux T, Blanco JG, Krynetski EY, et al.: Differing contribution of thiopurine methyltransferase to mercaptopurine versus thioguanine effects in human leukemic cells. Cancer Res. 2001; 61(15): 5810-5816. PubMed Abstract

18. Miller MB, Brackett J, Schafer ES, et al:: Prevention of mercaptopurine-induced hypoglycemia using allopurinol to reduce methylated thiopurine metabolites. Pediatr Blood Cancer. 2018; e27577.

PubMed Abstract | Publisher Full Text

19. Bostrom B: 6MP Allopurinol hypoglycemia patient data SPSS. figshare. Fileset. 2019.

http://www.doi.org/10.6084/m9.figshare.7666409.v1 


\section{Open Peer Review}

\section{Current Peer Review Status:}

\section{Version 1}

Reviewer Report 26 February 2019

https://doi.org/10.5256/f1000research.19418.r44317

(C) 2019 Rytting M. This is an open access peer review report distributed under the terms of the Creative Commons Attribution License, which permits unrestricted use, distribution, and reproduction in any medium, provided the original work is properly cited.

\section{Michael E. Rytting}

Departments of Pediatrics and Leukemia, The University of Texas MD Anderson Cancer Center, Houston, TX, USA

This report on two patients with hypoglycemia and increased 6MMP provides an interesting discussion of management of this unusual but significant problem. The description of the use of allopurinol along with the biochemical rationale for using the drug is very helpful, and should be of value to pediatric hematologists. The discussion, including the possibility of altering the effectiveness of chemotherapy, is fair and balanced, as well.

Is the background of the cases' history and progression described in sufficient detail? Yes

Are enough details provided of any physical examination and diagnostic tests, treatment given and outcomes?

Yes

Is sufficient discussion included of the importance of the findings and their relevance to future understanding of disease processes, diagnosis or treatment? Yes

Is the conclusion balanced and justified on the basis of the findings? Yes

Competing Interests: No competing interests were disclosed.

Reviewer Expertise: Pediatric leukemia and lymphoma

I confirm that I have read this submission and believe that I have an appropriate level of expertise to confirm that it is of an acceptable scientific standard. 
Reviewer Report 20 February 2019

https://doi.org/10.5256/f1000research.19418.r44316

(C) 2019 O'Brien M. This is an open access peer review report distributed under the terms of the Creative Commons Attribution License, which permits unrestricted use, distribution, and reproduction in any medium, provided the original work is properly cited.

\section{Maureen O'Brien}

${ }^{1}$ Cancer \& Blood Diseases Institute, Cincinnati Children's Hospital Medical Center, Cincinnati, OH, USA

2 University of Cincinnati School of Medicine, Cincinnati, $\mathrm{OH}$, USA

The authors provide an interesting report of the use of allopurinol to decrease 6-MMP levels and ameliorate 6MP-induced hypoglycemia. Their experience in these two cases is supported by other recent case reports with similar results. This article provides good background and discussion of the mechanism, as well as guidance regarding the risks of myelosuppression with this therapy and the need for $6 \mathrm{MP}$ dose reduction and close monitoring.

The authors should review the therapy details closely, particularly related to dosing. For patient \#1 they state that the methotrexate dose was $75 \mathrm{mg} / \mathrm{m}^{2}$ which is clearly a typo, but draws into question if other doses provided are correct.

Is the background of the cases' history and progression described in sufficient detail? Yes

Are enough details provided of any physical examination and diagnostic tests, treatment given and outcomes?

Yes

Is sufficient discussion included of the importance of the findings and their relevance to future understanding of disease processes, diagnosis or treatment?

Yes

Is the conclusion balanced and justified on the basis of the findings? Yes

Competing Interests: No competing interests were disclosed.

Reviewer Expertise: Pediatric oncology; leukemia

I confirm that I have read this submission and believe that I have an appropriate level of expertise to confirm that it is of an acceptable scientific standard. 
The benefits of publishing with F1000Research:

- Your article is published within days, with no editorial bias

- You can publish traditional articles, null/negative results, case reports, data notes and more

- The peer review process is transparent and collaborative

- Your article is indexed in PubMed after passing peer review

- Dedicated customer support at every stage

For pre-submission enquiries, contact research@f1000.com 